\title{
Simultaneous bilateral cerebral blood flow and metabolism with arteriographic correlation in unilateral brain infarction or haemorrhage ${ }^{1}$
}

\author{
E. BETETA, P. SCHEINBERG, O. M. REINMUTH, S. SHAFEY, AND S. SHIMOJYO \\ From the Department of Neurology, University of Miami School of \\ Medicine, Miami, Florida, U.S.A.
}

Methods for measuring cerebral blood flow and metabolism which are dependent upon the Fick principle require that blood obtained in cerebral venous sampling be representative of mixed cerebral venous blood. Studies by Kety and Schmidt (1945, 1948), Shenkin, Harmel, and Kety (1948), Scheinberg (1950a, b), and Munck and Lassen (1957) suggest that blood in each internal jugular vein is probably representative of all histological regions of the homo-

- lateral cerebral hemisphere and not necessarily of the entire brain. In normal subjects or patients without occlusive vascular disease, unilateral cerebral blood flow and metabolism measurements are probably representative of whole brain values. The purpose of this presentation is to demonstrate that this is not necessarily true in patients with unilateral brain infarction and, further, that prediction of cerebral metabolic data from clinical evaluation

- is impossible without arteriographic correlation, because of the enormous variability of circulatory patterns in the human brain.

\section{METHODS}

This study included 12 patients admitted to the neurology service at Jackson Memorial Hospital with acute vascular lesions of one cerebral hemisphere. The patients were carefully examined and followed in an effort to obtain as much clinical information as possible for correlative purposes. Arteriography was done to visualize the entire extracranial and intracranial arterial circulation. Ordinarily transbrachial catheterization arteriography was done but in certain cases it was necessary to resort to direct needle puncture of one or both carotid arteries in order to obtain an adequate study. A rapid cassette changer was utilized and usually six exposures made after each dye injection at the rate of one exposure per second in order to visualize the various stages of arterial and venous filling. Particular emphasis was placed on attempting to visualize sources and distribution of collateral circulation in subjects with demonstrated arterial stenosis or occlu${ }^{1}$ This work was supported by N.I.H. research grant no. HE 06641 and by the Meyer Gold Fund. sion, for it was felt that only in this manner could the cerebral blood flow studies be properly interpreted. Each patient had a routine electroencephalogram and brain scan $\left(\mathrm{Hg}^{203}\right.$ or $\mathbf{H g}^{197}$ labels) and whatever other studies were necessary to establish a diagnosis.

All the patients were seriously ill; three of them died relatively soon after the completion of these studies. Most of them had severe hypertensive vascular disease, but none of them showed signs of congestive failure at the time of the metabolic studies. In view of the unique circulatory problem in each instance, pertinent clinical data, including a description of the arteriogram, are included as an addendum to this paper.

For the metabolic studies the patients were brought to the laboratory in a fasting state. Needles were placed in both internal jugular bulbs in the manner originally described by Myerson, Halloran, and Hirsch (1927) and a Cournand needle was placed in a femoral or brachial artery. Cerebral blood flow was then measured by one or both of two techniques, the nitrous oxide method of Kety and Schmidt (1948) and by the $I^{131}$ iodoantipyrine method described by Reinmuth, Scheinberg, and Bourne (1965). Blood flow measurements were calculated for each side of the brain by using the venous values for that side in the case of the nitrous oxide method and by using the appropriate venous values and homolateral cerebral isotope uptake curves in the case of the $\mathrm{I}^{131}$ iodoantipyrine method. It is recognized that the values so obtained do not represent true unilateral blood flow values, but rather values which are weighted toward that particular side of the cerebrum. In the latter method, the geometry of the collimation dictates that each scintillation detector will 'see' more of the homolateral hemisphere and by virtue of the law of inverse squares be more greatly influenced by it.

Blood pressure was measured by auscultation every minute throughout the procedure and mean pressures obtained by the formula MP $=$ diastolic pressure $+1 / 3$ pulse pressure. Blood samples for oxygen, carbon dioxide, and $p \mathrm{H}$ were obtained immediately before and after the nitrous oxide procedure, and portions of each sample drawn during the isotope technique were utilized for these measurements. Blood samples were analysed for nitrous oxide using a slight variation of the method previously described by Kety and Schmidt (1948). Blood oxygen and 
carbon dioxide determinations were performed by either the manometric method of Peters and Van Slyke (1932) or by means of Clark-Severinghaus electrodes with an Instrumentation Laboratory apparatus. Blood $\mathrm{pH}$ was also measured directly in this apparatus. Values for $\mathrm{PO}_{2}$ obtained by the second method were converted to oxygen content by use of standard nomograms, oxygen capacity having been determined by the spectrophotometric method of Hickam and Frayser (1949). $\mathrm{PCO}_{2}$ was determined in each instance by means of the electrodes.

Cerebral oxygen consumption and cerebral vascular resistance were calculated as previously described by Kety and Schmidt (1948). Cerebral oxygen consumption in this study was calculated from the nitrous oxide value for cerebral blood flow and the mean of the oxygen extraction value obtained before and after the procedure. Since it was recognized in advance that blood flow values would be low, the nitrous oxide mixture was administered for 14 minutes in each instance to permit adequate time for brain-blood equilibrium to occur. Though we have conformed to the customary value of 1.0 as the partition coefficient of nitrous oxide between blood and brain, it is recognized that this value may not be applicable in brains $\bar{Z}$ with profoundly disturbed metabolism, as in infarction $\stackrel{\mathbb{D}}{\subseteq}$ or haemorrhage; however, it seems unlikely that this

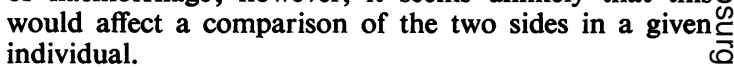

Similar studies were done in four 'normal' subjects, T patients with no known neurological lesion, in order to maintain a check on the technique of the laboratory. This $\stackrel{\bigcirc}{\supset}$ was particularly pertinent since the values obtained in the pathological subjects in the study were remarkably. abnormal and because it was felt that a further check on the validity of the side-to-side variations appearing in the patients with unilateral brain disease was essential.

\section{RESULTS}

The pertinent data are tabulated in Tables I and II. It is evident that there is essentially no difference between the two sides in any of the four 'normal'? subjects (Table I). This conforms with previous $\overrightarrow{\vec{\omega}}$ observations by Kety and Schmidt (1948) and $\omega$

TABLE I

BILATERAL STUDIES IN 'NORMAL' SUBJECTS

\begin{tabular}{|c|c|c|c|c|c|}
\hline \multirow[t]{2}{*}{ Subject } & \multirow{2}{*}{$\begin{array}{l}\text { Age } \\
\text { (yr.) }\end{array}$} & \multicolumn{2}{|l|}{$C B F$} & \multicolumn{2}{|c|}{$A-V O_{2}$} \\
\hline & & $\begin{array}{l}\left(N_{2} O\right) \\
R\end{array}$ & $\boldsymbol{L}$ & $\boldsymbol{R}$ & $L$ \\
\hline $\begin{array}{l}\text { W.J. } \\
\text { D.C. } \\
\text { O.B. } \\
\text { J.B. }\end{array}$ & $\begin{array}{l}26 \\
30 \\
49 \\
36\end{array}$ & $\begin{array}{l}88 \\
56 \\
60 \\
52\end{array}$ & $\begin{array}{l}86 \\
58 \\
60 \\
50\end{array}$ & $\begin{array}{l}5 \cdot 2 \\
6 \cdot 8 \\
7 \cdot 6 \\
6 \cdot 1\end{array}$ & $\begin{array}{l}5 \\
6\end{array}$ \\
\hline $\begin{array}{l}\text { CBF } \\
\text { A-VO, } \\
\text { CMRO, } \\
\text { ART O, } \\
\text { PA CO, } \\
\text { PV O2 } \\
\text { MAP } \\
\text { CVR }\end{array}$ & \multicolumn{5}{|c|}{$\begin{array}{l}\text { in } \mathrm{ml} / \mathrm{min} / 100 \mathrm{~g} . \text { brain } \\
\text { in vol. } \% \\
\text { in } \mathrm{ml} / \mathrm{O}_{2} / \mathrm{min} / 100 \mathrm{~g} . \text { brain } \\
\text { in } \% \mathrm{SAT} \text {. } \\
\text { in } \mathrm{mm} . \mathrm{Hg} \\
\text { in } \mathrm{mm} . \mathrm{Hg} \\
\text { in } \mathrm{mm} . \mathrm{Hg} \\
\text { in } \mathrm{mm} . \mathrm{Hg} / \mathrm{ml} . \text { blood } / 100 \mathrm{~g} . \text { brain } / \mathrm{min} \text {. }\end{array}$} \\
\hline
\end{tabular}

TABLE II

BILATERAL CEREBRAL METABOLIC FUNCTIONS IN UNILATERAL CEREBRAL VASCULAR LESIONS

\begin{tabular}{|c|c|c|c|c|c|c|c|c|c|c|c|c|c|c|c|c|}
\hline \multirow[t]{2}{*}{ Case } & \multirow[t]{2}{*}{$\begin{array}{c}\text { Age } \\
(y r .)\end{array}$} & $\begin{array}{l}\mathrm{N}_{2} \mathrm{O} \\
\text { ( } \mathrm{ml} \text {. } \\
\text { brai }\end{array}$ & \multicolumn{2}{|c|}{ Cerebral Blood Flow } & & \multicolumn{2}{|c|}{$\begin{array}{l}\text { Cerebral } \\
\text { A-VO, } \\
(\text { Vol. } \%)\end{array}$} & \multicolumn{2}{|c|}{$\begin{array}{l}\text { Cerebral } \mathrm{O}_{2} \\
\text { Consumption. } \\
\mathrm{N}_{2} \mathrm{O} \\
\left(\mathrm{ml} . \mathrm{O}_{3} / \text { min.l }\right. \\
10 \mathrm{O}_{\mathrm{g} . \text { brain })}\end{array}$} & \multirow[t]{2}{*}{$\begin{array}{l}\text { Arterial } \\
\mathrm{O}_{2} \\
\text { Saturation } \\
(\%)\end{array}$} & \multirow[t]{2}{*}{$\begin{array}{l}P A \mathrm{CO}_{2} \\
(\mathrm{~mm} . \mathrm{Hg})\end{array}$} & \multicolumn{2}{|c|}{$\begin{array}{l}P V \mathrm{O}_{2} \\
(\mathrm{~mm} . \mathrm{Hg})\end{array}$} & \multirow[t]{2}{*}{$\begin{array}{l}\text { Mean } \\
\text { Arterial } \\
\text { Pressure } \\
(\mathrm{mm} . \mathrm{Hg})\end{array}$} & \multicolumn{2}{|c|}{$\begin{array}{l}\text { Cerebral } \\
\text { Vascular } \\
\text { Resistance } \\
\text { (mm. Hg/ml. } \\
\text { blood } / 100 \mathrm{~g} . \\
\text { brain/min.) }\end{array}$} \\
\hline & & $\boldsymbol{R}$ & $\boldsymbol{L}$ & $\boldsymbol{R}$ & $L$ & $\boldsymbol{R}$ & $L$ & $\boldsymbol{R}$ & $\boldsymbol{L}$ & & & $\boldsymbol{R}$ & $L$ & & $\boldsymbol{R}$ & $\boldsymbol{L}$ \\
\hline $\begin{array}{l}\text { E.R. } \\
\text { J.B. } \\
\text { H.C. } \\
\text { E.T. } \\
\text { K.J. } \\
\text { A.M. } \\
\text { A.D. } \\
\text { M.J. } \\
\text { A.J. } \\
\text { D.L. } \\
\text { McK. } \\
\text { R.F. }\end{array}$ & $\begin{array}{l}49 \\
44 \\
48 \\
56 \\
65 \\
41 \\
46 \\
53 \\
72 \\
58 \\
54 \\
37\end{array}$ & $\begin{array}{l}36 \\
38 \\
29 \\
32 \\
61 \\
28 \\
35 \\
54 \\
49 \\
20 \\
49 \\
40\end{array}$ & $\begin{array}{l}31 \\
31 \\
25 \\
50 \\
45 \\
33 \\
30 \\
29 \\
52 \\
14 \\
45 \\
40\end{array}$ & $\begin{array}{l}662 \\
623 \\
- \\
580 \\
729 \\
- \\
395 \\
799 \\
432 \\
- \\
-\end{array}$ & $\begin{array}{l}626 \\
454 \\
- \\
739 \\
652 \\
- \\
340 \\
610 \\
384 \\
- \\
- \\
-\end{array}$ & $\begin{array}{l}8 \cdot 0 \\
5 \cdot 5 \\
4 \cdot 3 \\
5 \cdot 7 \\
4 \cdot 5 \\
2 \cdot 5 \\
4 \cdot 1 \\
4 \cdot 9 \\
4 \cdot 5 \\
7 \cdot 8 \\
6 \cdot 0 \\
7 \cdot 3\end{array}$ & $\begin{array}{l}7 \cdot 7 \\
4 \cdot 5 \\
4 \cdot 9 \\
5 \cdot 2 \\
5 \cdot 8 \\
2 \cdot 8 \\
4 \cdot 3 \\
5 \cdot 1 \\
4 \cdot 6 \\
8 \cdot 2 \\
6 \cdot 0 \\
6 \cdot 3\end{array}$ & $\begin{array}{l}2.9 \\
2 \cdot 1 \\
1 \cdot 3 \\
1 \cdot 8 \\
2 \cdot 7 \\
0 \cdot 70 \\
1 \cdot 4 \\
2 \cdot 7 \\
2 \cdot 2 \\
1 \cdot 6 \\
2.9 \\
2 \cdot 9\end{array}$ & $\begin{array}{l}2.4 \\
1.4 \\
1 \cdot 2 \\
2 \cdot 6 \\
2.6 \\
0.92 \\
1 \cdot 3 \\
1 \cdot 5 \\
2 \cdot 4 \\
1 \cdot 2 \\
2.7 \\
2.5\end{array}$ & $\begin{array}{l}93 \\
96 \\
95 \\
92 \\
95 \\
94 \\
95 \\
99 \\
98 \\
95 \\
88 \\
94\end{array}$ & $\begin{array}{l}36 \\
35 \\
40 \\
36 \\
36 \\
29 \\
32 \\
29 \\
40 \\
34 \\
44 \\
42\end{array}$ & $\begin{array}{l}25 \\
33 \\
39 \\
33 \\
43 \\
33 \\
48 \\
47 \\
42 \\
26 \\
31 \\
29\end{array}$ & $\begin{array}{l}27 \\
36 \\
36 \\
32 \\
41 \\
31 \\
47 \\
48 \\
43 \\
25 \\
30 \\
31\end{array}$ & $\begin{array}{r}118 \\
139 \\
158 \\
103 \\
95 \\
142 \\
168 \\
155 \\
127 \\
78 \\
127 \\
133\end{array}$ & $\begin{array}{l}3 \cdot 2 \\
3 \cdot 6 \\
5 \cdot 4 \\
3 \cdot 1 \\
1 \cdot 6 \\
5 \cdot 0 \\
4 \cdot 8 \\
2 \cdot 9 \\
2 \cdot 5 \\
3 \cdot 9 \\
2 \cdot 6 \\
3 \cdot 3\end{array}$ & $\begin{array}{l}3 \cdot 8 \\
4 \cdot 5 \\
6 \cdot 4 \\
2 \cdot 0 \\
2 \cdot 3 \\
4 \cdot 3 \\
5 \cdot 6 \\
5 \cdot 3 \\
2 \cdot 4 \\
4 \cdot 9 \\
2 \cdot 8 \\
3 \cdot 3\end{array}$ \\
\hline
\end{tabular}

Italics denote side of pathology. 
Scheinberg (1950a, b). It is felt that the data in Table II must be studied patient by patient, for it is the essence of this text that the individual variations of cerebral circulation in patients with cerebral vascular disease cause statistical analysis of this type of data to be a scientific absurdity.

It is obvious that the values for cerebral blood flow and cerebral oxygen consumption in practically all these patients were low, in some instances extraordinarily low. The greatly reduced values for cerebral oxygen consumption could be correlated with the profound disturbance of brain function present in these individuals, and there seemed to be a rough correlation between the extent of brain damage, the size and extent of the infarct or haemorrhage, and the degree of alteration of cerebral oxygen consumption. It must be remembered that the majority of these patients were severely obtunded at the time of their study. There was usually a proportionate reduction from normal in cerebral blood flow as measured by the $\mathbf{I}^{131}$ iodo-antipyrine technique when compared with the nitrous oxide values in the same patient.

The greatest difference between the two sides was recorded in two patients (E.T. and M.J.) in whom arteriography revealed complete occlusion of a major artery with little or no filling of the vessels on the diseased side from other arterial sources. Subject E.T. had an old infarction of the right cerebral hemisphere and recovered very little motor function. Arteriography revealed complete occlusion of the right internal carotid artery and no filling of the right middle cerebral artery from the opposite - carotid or from extracranial anastomoses. There was some evidence of communication between the vertebral-basilar system and the right carotid system from a large right posterior communicating artery. Cerebral blood flow on the right was $32 \mathrm{ml} . / \mathrm{min} . / 100$ g. brain compared with $50 \mathrm{ml}$. on the left; by the iodo-antipyrine method the values were $580 \mathrm{ml}$. and $739 \mathrm{ml}$. respectively. Cerebral oxygen consumption was proportionately reduced on the right. A similar situation obtained in M:J. whose arteriogram revealed occlusion of the left middle cerebral artery and no evidence of collateral circulation. The reduction in blood flow and metabolism on the left side was corroborated by the iodo-antipyrine values. The markedly reduced cerebral oxygen consumption of $1.5 \mathrm{ml} .0_{2} / 100 \mathrm{~g}$. brain on the left would appear to be a reflection of the large haemorrhagic infarction in the left hemisphere.

Subject K:J. had no neurological defect at the time of the study, but had a history of recurrent transient ischaemic episodes in the left carotid circulation. $\mathrm{N}_{2} \mathrm{O}$ blood flow studies revealed a striking reduction of flow on the left ( $>24 \%$ ). Iodo-antipyrine blood flow studies also revealed comparatively reduced blood flow on the left, but quantitatively less. Of great interest is the finding that cerebral oxygen consumption was equal on the two sides, a physiological confirmation of the absence of unilateral hemisphere disease clinically. Arteriography provides an explanation for the reduced left-sided blood flow, because it showed the left internal carotid artery to be severely stenotic, the lumen being reduced to $2 \mathrm{~mm}$.

Four of the patients (E.R., A.D., A.J., and McK.) can be considered together, for they represent the problem of brain infarction without demonstration of significant arterial occlusive disease by arteriography. In each instance there was only a minor difference in cerebral blood flow between the two sides, though it was always somewhat less on the side of the infarction. The important consideration is that there seems to be little difference in blood flow between the two sides in the absence of demonstrable occlusion. Similarly, reduction of cerebral oxygen consumption on the side of the infarction was proportionately small, though consistent. This would appear to correlate with the clinical impression that each of these patients suffered from a small capsular infarction, and that the profound motor involvement was a consequence of the strategic location, rather than the size, of the lesion. Of further interest is that each of these patients made an excellent recovery from the ictus, suggesting that clinical recovery might be a function of maintenance of arterial circulation on the side of the lesion and the size of the infarction.

Subjects H.C. and R.F. are similar in that no arterial occlusive disease was observed in either by arteriogram, and both had intracerebral haematomas, not brain infarctions. Cerebral blood flow was not significantly different on the two sides, nor was cerebral oxygen consumption despite clinical evidence of massive disruption of motor function.

The arteriogram on subject J.B. showed complete occlusion of the left internal carotid artery, but the left middle cerebral circulation filled slowly from the vertebral-basilar system and the patient's infarction was small. There was an evident reduction in cerebral blood flow by both methods of measurement, and a strikingly reduced cerebral oxygen consumption on the side of the infarction.

Subject A.M. had evidence of severe generalized cerebral damage at the time of the study. He was believed to have bilateral cerebral hemisphere infarctions and he was comatose. Cerebral blood flow and oxygen consumption were profoundly depressed, the values for cerebral oxygen consumption being significantly lower than any we have previously recorded. Arteriograms revealed severe stenosis of 
both internal carotid arteries. Subject D.L. similarly had bilateral hemisphere lesions, and arteriography revealed occlusion of the right middle cerebral artery and the left internal carotid artery. Right middle cerebral artery occlusion had occurred clinically two years before and the patient had recovered neurological function by virtue of cross circulation from the left carotid. Following occlusion of the left carotid artery, the patient developed a massive left hemisphere infarction with evidence of lesser damage in the right hemisphere. The patient was comatose at the time of study and while cerebral blood flow and oxygen consumption values were diminished bilaterally, the reduction was appreciably greater on the left, the side of the recent occlusion.

\section{DISCUSSION}

In any given individual it is impossible to predict the degree of mixing of cerebral blood which will occur before it appears in the internal jugular veins. There is substantial disagreement among anatomists as to the incidence of true confluence of the sagittal and straight sinuses. Most anatomical reports indicate that true torculars are rare. In his classic study Edwards (1931) found it to occur in only six of 50 cases, or in $12 \%$. Gibbs and Gibbs (1934) and Batson (1944) reported a similar incidence of torculars from their observations. There is good reason to believe that true mixing of blood from both hemispheres is far from complete.

It is generally accepted that, in addition to anatomical configuration of vessels, streaming of blood is an important factor in determining the eventual destination of any given unit of blood. Such streaming persists in the venous circulation. Shenkin et al. (1948) determined by dye injection studies that two-thirds of the blood carried to the brain by one internal carotid artery is drained by the homolateral internal jugular vein.

This being true, it is apparent that if arterial inflow is significantly reduced in one hemisphere, this should be reflected in the homolateral cerebral venous outflow. A variety of unknowns may influence the validity of this concept. These include the extent to which other arterial sources contribute blood to the involved hemisphere. This is purely an individual phenomenon and is a function of the efficiency of potential collateral channels from the opposite carotid, by way of the anterior cerebral artery, from the vertebral-basilar system through the posterior communicating artery, from the external carotid system via the external carotid-ophthalmic anastomosis, and from anastomoses of various major branches of the internal carotid on the involved side. These are the same factors which appear to influence recovery from local cerebral ischaemia due to oc- $\bar{z}$ clusive cerebral vascular disease and which are: $\stackrel{\mathbb{D}}{=}$ responsible for the prevention of infarction when a major vessel becomes occluded.

The extent to which true mixing of blood from various histological areas of the brain occurs has never been adequately established. There is a highly $\frac{\rho}{?}$ developed intracerebral and extracerebral anastomotic system of veins in man, anatomically con- $\vec{z}$

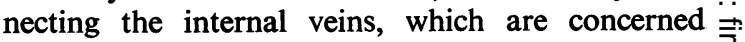
primarily with the drainage of the ventricular surface, choroid plexuses, deep medullary substance, caudate nuclei, and dorsal portions of the lenticular $\underline{\underline{D}}$ nuclei and thalamus, with the external cerebral $\frac{\bar{s}}{\partial}$ veins. There is practically no information which $\stackrel{\mathbb{Q}}{\varrho}$ bears on the degree to which this anastomotic system functions in the absence of lesions com- $\vec{O}$ pressing groups of veins or venous occlusion. It is $?$ likely that the anastomoses are potential ones, $\vec{\omega}$ functioning in the event of need, similar to the $\stackrel{\mathscr{S}}{\circ}$ arrangement on the arterial side, and probably even $\overline{3}$ more variable. Well-known clinical facts make it quite clear that the anastomoses are not always $\underset{\infty}{\infty}$ usefully functional, for thrombosis of superficiat cortical veins may result in massive brain infarctio $\vec{\Phi}_{\text {W }}^{\omega}$ The inadequacy of this communicating system fo of rapid adjustments is further evidenced by the almogit invariably catastrophic result which follows ligation of the superior sagittal sinus in its posterior half Clearly if the anastomotic veins were truly effective the superficial veins could drain into the deep veins in such an instance. There is much to recommend to conviction that in the normal person, the superficial of veins do, in fact, drain into the superior sagittal o sinus and the deep veins into the vein of Galen and hence into the straight sinus.

If these deductions are correct, it is obvious that blood from the superficial venous system of both $\frac{\circ}{\Phi}$ hemispheres may well drain into one lateral sinus, $\stackrel{\varrho}{\rightleftarrows}$ and that from the deep venous system of both hemi- $\frac{0}{3}$ spheres into the other lateral sinus in the absence of a torcular. In fact, then, the degree of mixing of cerebral venous blood is a rather complex function of individual anatomical design of the superior sagittal, straight, and lateral sinuses, the physicalo factors of streaming, and the effects on both the $\frac{5}{3}$ arterial and venous systems of intracranial disease.

Finally there is a significant portion of the brain whose venous drainage does not leave the skull via the internal jugulars. An unknown and undoubtedly의 variable portion of blood from the cavernous $\rightarrow$ sinus (which drains portions of the inferior surfaces of the hemispheres, mesencephalon, and pons) drains $N$ inferiorly into the basilar plexus which extends along the basilar portion of the occipital bone to the $\mathbb{N}$ foramen magnum and there communicates with the 
venous plexuses of the vertebral canal. The veins of the medulla and some of those of the inferior pons also make caudal connexions with the veins of the spinal cord. The point of this is that these areas are necessarily not represented in the "mixed cerebral venous blood' utilized to measure cerebral blood flow despite the certainty that they contribute greatly, even disproportionately, to the patient's clinical state. A lower pontine or medullary infarction may result in profound clinical abnormalities, with significant alterations in the patient's state of awareness and yet not in any way affect the measurement of cerebral blood flow or metabolism as reflected in internal jugular blood. The speciousness of attempts to correlate a patient's state of consciousness and neurological state with alterations in cerebral blood flow or metabolism without absolutely definitive information as to the location of the lesion is, we believe, evident, and it is for this reason that much of this type of statistical correlation, previously done, has little scientific or clinical merit. In this we do not except ourselves.

The anatomical bases for mixing of blood from various histological tissues of the brain originally cited by Kety and Schmidt (1945) in their justification of this important assumption in the validity of the nitrous oxide technique does not, therefore, appear to us to be adequate. The same objections would apply to any method utilizing unilateral internal jugular samples for blood flow measurement. Fortunately this objection would probably not matter in the majority of normal individuals or subjects with generalized brain disorders, but could be of considerable importance in subjects with unilateral brain disease. In the special circumstances of cerebral vascular disease, in which circulatory patterns cannot be clinically predicted, bilateral cerebral venous samples are required along with the most definitive arteriographic and clinical correlation. The observation that unilateral disease of the brain or unilateral vascular anomalies may result in bilateral alterations of cerebral venous blood, as in the two patients with arteriovenous shunts originally reported by Kety and Schmidt (1945) in no way vitiates this conclusion, for particular drainage patterns of these individuals may have been propitious for this type of mixing. An entirely different situation may occur, as in the two cases of arteriovenous anomalies reported by Bessman, Hayes, Alman, and Fazekas (1952), or in the two cases reported by Munck and Lassen (1957), wherein blood flow on the side of the shunt was much greater than on the opposite side. Our own experience has been similar to the latter report.

The aforementioned unpredictable anatomical variations may likewise account for the discrepancies which have been reported concerning bilateral jugular blood. Ferris, Engel, Stevens, and Logan (1946) found significant differences in one-third of their subjects at rest and in the majority during hyperventilation. Gibbs, Lennox, and Gibbs (1945) found that of seven epileptics with unilateral cerebral pathology, the arterial-cerebral venous oxygen difference was greater on the side of the pathology in four and equal in three. In addition, six schizophrenic patients showed unequal arterial-cerebral venous oxygen differences, despite the absence of unilateral clinical signs. Unfortunately they do not provide sufficient clinical data with which to make a correlation.

Himwich, Homburger, Maresca, and Himwich (1947) reported significant differences in cerebral blood flow and oxygen consumption determined by the nitrous oxide method between the two sides in several subjects, and concluded that the cortical component is represented by the side with the higher value for oxygen consumption, since this value was always depressed by pentothal anaesthesia. They offered no clinical information about these subjects.

Bilateral cerebral blood flow studies by Kety and Schmidt, using the nitrous oxide technique (1945), showed the standard deviation of the individual differences for cerebral oxygen consumption to be only slightly greater than the standard deviation of the differences between duplicate determinations on the same side in another series of patients. They concluded that the differences between the right and left internal jugular measurements were within the experimental error of the method. In reality there is no absolute assurance that cerebral blood flow or metabolism does not change in a short period of time in any given subject, so that their standard of comparison itself requires confirmation. Of the eight patients without arteriovenous shunts, the maximum percentage difference between right and left was $21 \%$, with a mean of about $10 \%$. Studies by Scheinberg $(1950 a, b)$ reported similar results, utilizing a modification of the original Kety and Schmidt technique. These included patients with cerebral vascular disease, but accompanying data are inadequate to evaluate the clinical problem.

Munck and Lassen (1957) reported statistically significant differences between right and left sides in two-thirds of 38 patients, utilizing Krypton ${ }^{85}$. This method is considered more exact, and therefore more sensitive than the nitrous oxide technique because each set of graphs is determined by 20 analyses, rather than by the 10 of the nitrous oxide method. This increased sensitivity may be responsible for their observations. In reality the percentage variations of the difference between the two sides from the means of the two sides does not differ 
appreciably from those reported by Kety and Schmidt (1945) or Scheinberg (1950a, b). In addition the authors do not provide sufficient clinical data with which to evaluate the exact nature of the brain disease.

One cannot compromise the discrepancies among all these studies, but if conclusions are based solely upon observations on normal individuals, as picked out of each of the above studies, it is apparent that either inert gas method reveals comparable values for cerebral blood flow and metabolism between right and left sides in about $85 \%$ of the instances, though variations are perforce obliged to occur. Since there is no systematic difference between the two sides, means of unilateral values will be representative of the whole brain, though less accurate than bilateral measurements. In patients with unilateral brain disease, and particularly unilateral occlusive vascular disease, however, bilateral studies are essential for adequate measurement, and precise clinical and arteriographic correlations are necessary for adequate interpretation.

Contrasted to bilateral cerebral metabolic values for normal individuals as determined in this laboratory now and previously, the side-to-side differences between cerebral blood flow and oxygen consumption reported in this study are all the more striking. The greatest differences in blood flow occur when arterial occlusion is complete and there is meagre and delayed collateral flow, as illustrated in patients E.T., M.J., and J.B. Cerebral vascular resistance is proportionately increased on the pathological side.

Patient K.J. illustrates that when there is sufficient circulation to prevent infarction, cerebral oxygen consumption is maintained despite reduced homolateral flow. Patients E.R., A.D., A.J., and McK. demonstrate the correlation between lack of occlusive disease by arteriography and absence of significant blood flow differences between the two sides. They also demonstrate that a small pathological defect (capsular infarction) may produce important neurological defects, but not alter homolateral brain oxygen consumption, pointing to the importance of the size of the infarction in determining the extent of alteration of brain metabolism.

The effect of intracerebral bleeding (H.D. and R.F.) in the absence of occlusive arterial disease was to depress brain blood flow and oxygen consumption bilaterally. One can only speculate that the haematoma, unlike brain infarction, was totally excluded from the circulation and therefore did not contribute to the measurement of blood flow per unit weight of brain tissue. Certainly there was ample clinical and arteriographic evidence that the blood clot was not only locally destructive but behaved as a mass lesion influencing the function of both hemispheres. Unfortunately, iodo-antipyrine blood flow studies were not available in these two subjects.

As has been repeatedly emphasized, the nitrous $\underset{0}{=}$ oxide method measures cerebral blood flow per unit 0 weight of brain tissue. It is theoretically possible, therefore, for a portion of the brain to be removed or $\stackrel{5}{=}$. totally divested of its circulation without influencing measured flow, provided that the remaining portion? of the brain is unaffected and normal. Though this $\vec{F}$ has been offered in the past as an objection to the $\stackrel{0}{?}$ usefulness of this method, this study indicates that in practice such a situation rarely obtains. It is likely $\frac{\bar{D}}{\bar{D}}$ that even if a portion of the infarcted tissue is ex- $\frac{\vec{\sigma}}{\vec{D}}$

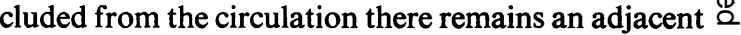
and probably larger area of ischaemic tissue in which blood flow is reduced and metabolism lowered, $\overrightarrow{0}$ and this does contribute to the flow measurement.

To our knowledge no similar studies are available $\vec{\omega}$ in the literature for comparison. Cerebral metabolic $\stackrel{5}{S}$ studies have been reported in cerebral vascular disease (Scheinberg, 1950a, b), (Fazekas, Yuan, i Callow, Paul, and Alman, 1962), organic dementias 9 (Lassen, Munck, and Tottey, 1957), senilitw (Freyhan, Woodford, and Kety, 1951), and arteriof e् sclerosis (Shenkin, Novak, Goluboff, Soffe, and 을 Bortin, 1953), but each study has been incomplete lacking either clinical information, arteriographie $\vec{\square}$ correlation, or bilateral observations, and, in some instances, all of these. In most instances severe की hypertensive and arteriosclerotic vascular disease. $\vec{P}$ was associated with profound reduction in cerebra $\overrightarrow{\mathscr{Q}}$ blood flow and metabolism, a finding confirmed by this present study.

\section{SUMMARY}

Simultaneous bilateral determinations of cerebral $\stackrel{\circ}{\stackrel{Q}{\perp}}$ blood flow and oxygen consumption were made in $\overrightarrow{\vec{F}}$ 12 subjects with predominantly unilateral cerebral $\frac{9}{3}$ vascular disease. Blood flow determinations were made by the nitrous oxide method in all subjects and also by the $\mathbf{I}^{131}$ iodo-antipyrine method in seven of the subjects.

Each patient was carefully evaluated clinically and arteriography was performed to visualize the entire extra- and intracranial cerebral circulation for comparison with the blood flow studies. Statistical analysis is not attempted since each patient represented an individual and unique haemodynamic and metabolic problem.

Cerebral blood flow and oxygen consumption are greatly reduced on the side of the infarction as $N$ compared to the intact hemisphere in those instances in which arterial occlusion is complete and collateral circulation is inadequate or meagre. Where there is 
adequate circulation to prevent infarction cerebral oxygen consumption is maintained despite arterial stenosis which greatly reduces homolateral blood flow.

In patients with cerebral infarction whose arteriograms failed to demonstrate occlusive arterial disease, cerebral blood flow was not greatly reduced on the side of the infarction. Cerebral oxygen consumption was not greatly reduced on the side of small capsular infarctions despite profound neurological disturbance. The extent of reduction in cerebral oxygen consumption correlated best with the size of the infarction.

In two patients with intracerebral haematomas, cerebral blood flow and oxygen consumption were reduced from normal, but the reduction was not greater on the side of the haematoma.

Severe occlusive cerebral vascular disease caused profound reduction in cerebral blood flow and metabolism, but this is not incompatible with survival and even considerable improvement.

The anatomy of cerebral venous mixing is discussed in the light of these results and previous observations are reviewed. There is no doubt that unilateral brain disease may be reflected predominantly in homolateral jugular venous blood; cerebral blood flow measurements under these circumstances must be bilateral in order to obtain a true reflection of 'mean' values from the whole brain.

There is excellent qualitative correlation between cerebral blood flow values in the same individual as measured by the nitrous oxide and the $I^{131}$ iodoantipyrine methods. Electroencephalographic correlation with the side and location of the infarction or haematoma occurred in every patient.

Bilateral cerebral blood flows were measured in four patients without evidence of unilateral brain disease for comparison. Correlation between the two sides was excellent in all of them. This is consistent with many previous observations.

\section{CASE HISTORIES}

CASE 1 E.R., aged 49, had a history of hypertension and diabetes. On 1 February 1964, he suddenly developed right hemiparesis. On examination blood pressure was $160 / 130 \mathrm{~mm} . \mathrm{Hg}$. There was peripheral atherosclerosis and cardiomegaly but no signs of congestive failure. He was alert; orientated; he had right brachial monoplegia with mild paresis right leg; mild expressive and receptive dysphasia; no visual field defect; bilateral Babinski; no sensory defect. The patient was studied four days after admission and physical findings were unchanged. Haematocrit 44; cerebrospinal fluid normal. Brain scan showed increased uptake in left parietal region. E.E.G. showed circumscribed slow focus in left temporal region. Ophthalmodynamometry gave (L) $140 / 110$, (R)
125/104. Arteriograms showed $20 \%$ stenosis of right vertebral artery. No other evidence of stenotic or occlusive vascular disease. Venous phase revealed bilateral lateral sinus drainage following injection of either side.

Diagnosis was left subcortical infarction, small, without arteriographic evidence of arterial occlusion; healed cardiovascular disease; diabetes mellitus; history of lues, treated.

The patient recovered progressively and showed only mild right hyperreflexia six months after the onset of the illness.

CASE 2 J.B., aged 44, six weeks before admission noted a transient episode of right-sided weakness and dysphasia. He recovered completely except for difficulty with memory. On 22 January 1964, he developed right hemiparesis and dysphasia and appeared to be severely confused. He had a history of hypertension for several years. Blood pressure was $210 / 110 \mathrm{~mm} . \mathrm{Hg}$, cardiomegaly but no congestive failure, severe peripheral atherosclerosis. On day of study, 10 February 1964, he had mild dysphasia, and was disorientated and confused but not lethargic. Grade II right hemiparesis, right asterognosia, dyslexia, dyscalculia, diminished optico-kinetics to left. Cerebrospinal fluid was normal. Arteriograms showed occlusion of the left internal carotid artery at the bifurcation; moderate stenosis of right internal carotid, delayed filling of left hemisphere from vertebral-basilar system. On the E.E.G. a large slow wave focus was seen in the left fronto-parietal areas. Ophthalmodynamometry showed (R) 150/76, (L) 122/55.

The patient improved but remained with impaired memory and intellectual functioning. Hemiparesis and dysphasia disappeared.

CASE 3 H.C., aged 48, was found stuporous on 6 February 1964. He had no known previous history of cardiovascular disease. He was studied on 12 February 1964. when cardiomegaly was apparent. Blood pressure was $210 / 150 \mathrm{~mm} . \mathrm{Hg}$, stuporous; right flacid hemiplegia; right hemianopsia, hemihypalgesia. The cerebrospinal fluid was xanthochromic (37 R.B.C.s, 46 mononuclears, protein $76 \mathrm{mg} . \%$ ). An arteriogram showed a slight shift of the left anterior cerebral artery to the right with lateral displacement of the angiographic sylvian point, with rotation of the sylvian vessels, good filling of carotids, vertebrals, and middle cerebral arteries, indicative of intracerebral haematoma. The E.E.G. showed circumscribed slowing over the left anterior hemisphere and generalized abnormalities consistent with a comatose state. A brain scan showed an area of increased uptake on the left side. The final diagnosis was left intracerebral haematoma, gradually resolved; healed cardiovascular disease.

The patient gradually improved. Present residual is right spastic hemiparesis, grade II. Dysphasia has disappeared.

CASE 4 E.T., a 56-year-old white man, had a history of grand mal seizures and right cerebral hemisphere infarction in 1962 and of recurrent seizures subsequently. $\mathrm{He}$ also had a history of acute and chronic alcoholism. On examination he was alert, orientated, with residual left hemiparesis, grade II. Cerebrospinal fluid was 
normal. An arteriogram showed complete occlusion of the right internal carotid artery, and right subclavian stenosis. No filling of the right middle cerebral artery from either carotid but late filling from a large right posterior communicating artery. Ophthalmodynamometry showed (R) 150/140, (L) 130/90. Disorganization of rhythms compatible with a lesion in the anterior right hemisphere was seen on the E.E.G.

Final diagnosis was (1) infarction, old right cerebral hemisphere, due to thrombosis of right internal carotid artery; (2) chronic alcoholism; (3) cerebral seizures, grand mal, aetiology unknown.

The patient retained a grade II left spastic hemiparesis.

CASE 5 K.J., a 65-year-old coloured woman, had a history of recurrent transient ischaemic attacks of the left carotid system with other episodes suggestive of vertebral-basilar insufficiency as well. The patient had recovered completely from all attacks. On physical examination blood pressure was $150 / 85 \mathrm{~mm}$. Hg. No neurological defect. An arteriogram showed stenosis of the left internal carotid artery (lumen reduced to $2 \mathrm{~mm}$.), atherosclerotic changes in supraclinoid portion of left internal carotid artery; $40 \%$ stenosis of right subclavian artery. Opthalmodynamometry gave (R) 60/20, (L) 102/42. No abnormality was seen on the E.E.G.

Diagnosis was recurrent ischaemic attacks of carotid and vertebral basilar systems due to atherosclerosis and major stenosis in the left internal carotid artery.

The patient subsequently expired after thromboendarterectomy.

CASE 6 A.M., a 41-year-old coloured man, had a history of severe, poorly controlled diabetes. On 14 January 1964 he became stuporous and was found to have massive subarachnoid bleeding. He had no lateralizing signs until arteriography, at which time he apparently had a right cerebral hemisphere infarction. He then became obtunded and had a right hemiparesis and partial right III nerve palsy. Blood pressure was $230 / 130 \mathrm{~mm}$. $\mathrm{Hg}$. An arteriogram showed stenotic lesions at the origins of each internal carotid artery; questionable $3 \mathrm{~mm}$. aneurysm at origin of left middle cerebral artery. The E.E.G. showed a slow wave focus in the left cerebral hemisphere.

The diagnosis was spontaneous subarachnoid haemorrhage due to aneurysm of the right middle cerebral artery, infarction of a portion of the right cerebral hemisphere and probably bilateral hemisphere infarction; Hypotensive cardiovascular disease.

The patient developed a communicating hydrocephalus. He improved after a shunting procedure and had little remaining hemiparesis.

CASE 7 A.D., a 46-year-old white man, had a sudden onset of right hemiparesis and dysphasia on 23 February 1964. He had a three-year history of recurrent episodes of transient ischaemic attacks with intermittent diplopia and other signs suggestive of brain-stem ischaemia and of hypertension for at least four years. On examination his blood pressure was $220 / 140 \mathrm{~mm}$. Hg. He was alert; right spastic hemiplegia; horizontal and vertical nystagmus; sensation was intact; no dysphasia. Cerebrospinal fluid was normal. He was studied on 2 March 1964. An $\bar{z}$

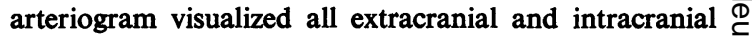
cerebral vessels and no abnormalities were noted. An E.E.G. showed a focus of high-voltage slow activity in the left temporal area. Ophthalmodynamometry gave $\underset{0}{0}$ (R) $150 / 100$, (L) 150/100. The diagnosis was (1) infarction 7 in the left internal capsule due to thrombosis of a branch of the left middle cerebral artery; (2) history of vertebralbasilar insufficiency.

The patient improved very slowly. Six months after the ictus he was able to walk with a cane.

CASE 8 M.J., a 53-year-old coloured woman, two years before admission had a right hemiparesis which cleared $\frac{C}{O}$ in two days. She had a history of hypertension for several $\overline{\bar{\omega}}$ years but no signs of congestive failure. She experienced $\vec{\nabla}$ the sudden onset of right-sided weakness on 25 February $\triangle$ 1964. On examination blood pressure was $240 / 130 \mathrm{~mm}$. के Hg. Alert, global aphasia, spastic right hemiplegia, $\vec{\circ}$ right homonymous hemianopsia, right hemihyperaesthesia. Cerebrospinal fluid was normal. She was studied $\overrightarrow{\vec{\omega}}$ on 4 March 1964. An arteriogram showed narrowing of $\stackrel{\omega}{\circ}$ the left internal carotid artery, occlusion of the left middle cerebral artery, and atherosclerosis of both anterior $\frac{7}{0}$ cerebral arteries, left ventricular dilatation. Slow and i minor filling of left middle cerebral artery domain via collateral from anterior cerebral artery. An E.E.G. showed a focus of slow activity left temporal. The e diagnosis was thrombosis of the left middle cerebra artery with a large infarction of left cerebral hemisphere Hypotensive cardiovascular disease; atherosclerosisgeneralized, severe. The patient improved slowly but was readmitted to hospital on 26 March 1964 with dysphage and dysarthria and expired one day later.

CASE 9 A.J., a 72-year-old white man, was a knowit hypertensive for 20 years. On 8 February 1964 he suddenly had a left hemiparesis. The patient was studied on 23 March 1964. On examination his blood pressure was $220 / 120 \mathrm{~mm}$. Hg. There was severe sclerosis of peripheral $\bar{\partial}$ vessels; an abdominal aortic aneurysm; he was alert and cooperative; left hemiparesis grade II. No sensory or $\stackrel{\circ}{\mathbb{Q}}$ visual signs. Cerebrospinal fluid was normal. An arterio- 을 gram showed mild stenosis $(20 \%)$ of right internal carotid $\vec{F}$ artery just above bifurcation and also in the intra- 3 cranial portion; diffusely dilated basilar artery, and an E.E.G. mild slow focus in the right hemisphere. The diagnosis was (1) infarction (small) right capsular area; (2) diffuse cerebral atherosclerosis.

The patient improved progressively; emotional lability; grade II paresis left upper extremity only.

CASE 10 L.deJ., a 58-year-old white woman, had a $\stackrel{\text { }}{2}$ history of rheumatic heart disease with atrial fibrillation, compensated. On 20 May 1960, she experienced sudden 윽 aphasia, right hemiplegia, right homonymous hemian- $D$ opsia; head and eyes deviated to the left, severely음 obtunded. Three years before she had a right middle cerebral artery thrombosis demonstrated by arterio- $\sigma$ graphy. The patient was studied on 1 June 1964. An arteriogram showed old right middle cerebral artery $\mathrm{O}$ occlusion (? embolism) and occlusion of the left internal $\omega$ 
carotid artery. An E.E.G. showed a slow focus in the anterior left hemisphere and a brain scan increased uptake in the left parietal area. The diagnosis was (1) occlusion left internal carotid artery due to embolism with resultant large left hemisphere infarction; (2) old right hemisphere infarction (3) rheumatic heart disease (all confirmed at necropsy.

The patient expired on 7 June 1964.

CASE 11 J.McK., a 54-year-old coloured woman, known to be hypertensive and diabetic since 1959, was under medical therapy. Forty-eight hours before admission on 25 October 1964, she noted coldness and numbness in the left extremities and the sudden onset of left hemiparesis. She was studied on 6 November 1964. On examination she was obese, conscious, orientated; blood pressure 200/130 mm. Hg. Grade III left hemiparesis with spasticity. No visual defects. An arteriogram showed left vertebral artery stenosis at its origin; the right vertebral artery was intact. Mild narrowing right internal carotid artery intracranially; $50 \%$ stenosis of basilar artery below its bifurcation. Cerebrospinal fluid was normal, as was the E.E.G.

The diagnosis was (1) small right capsular infarction; (2) stenosis left vertebral and basilar arteries. The patient improved progressively.

CASE 12 R.F., a 37-year-old coloured woman, had a two-year history of hypotensive cardiovascular disease She experienced the sudden onset of left hemiplegia and hypalgesia with somnolence on 6 September 1964. She was studied on 23 September1964. On examination she had left hemiplegia, blood pressure was $190 / 130 \mathrm{~mm}$. Hg. Dense hemihypalgesia. The cerebrospinal fluid was xanthochromic. An arteriogram showed a shift of the internal cerebral vein $1.5 \mathrm{~cm}$. to the left and evidence of a mass lesion in the central gray matter on the right.

The diagnosis was intracerebral haematoma in the region of the right basal ganglia and thalamus. Hypotensive cardiovascular disease. The patient improved slightly.

The authors wish to express their appreciation to $\mathbf{B}$. Bourne, Ph.D., for laboratory assistance, and to Raoul Busto, Justo Corripio, and Arturo Monteil for technical assistance.

\section{REFERENCES}

Batson, O. V. (1944). Anatomical problems concerned in the study of cerebral blood flow. Fed. Proc., 3, 139-144.
Bessman, A. N., Hayes, G. J., Alman, R. W., and Fazekas, J. F. (1952). Cerebral hemodynamics in cerebral arteriovenous vascular anomalies. Report of two cases. Med. Ann. D.C., 21, 422-425.

Edwards, E. A. (1931). Anatomic variations of the cranial venous sinuses. Arch. Neurol. Psychiat. (Chic.), 26, 801-814.

Fazekas, J. F., Yuan, R. H., Callow, A. D., Paul, R. E., and Alman, R. W. (1962). Studies of cerebral hemodynamics in aortocranial disease. New Engl. J. Med., 266, 224-228.

Ferris, E. B., Engel, G. L., Stevens, C. D., and Logan, M. (1946), The validity of internal jugular venous blood in studies of cerebral metabolism and blood flow in man. Amer. J. Physiol., $147,517-521$.

Freyhan, F. A., Woodford, R. B., and Kety, S. S. (1951). Cerebral blood flow and metabolism in psychoses of senility. J. nerv. ment. Dis., 113, 449-456.

Gibbs, E. L., and Gibbs, F. A. (1934). The cross section areas of the vessels that form the torcular and the manner in which flow is distributed to the right and to the left lateral sinus. Anat. Rec., $59,419-426$.

-, Lennox, W. G., and Gibbs, F. A. (1945). Bilateral internal jugular blood. Comparison of A-V differences, oxygendextrose ratios and respiratory quotients. Amer. J. Psychiat., 102, 184-190.

Hickam, J. B., and Frayser, R. (1949). Spectrophotometric method determination of blood oxygen. J. Biol. Chem., 180, 457-465.

Himwich, W. A., Homburger, E., Maresca, R., and Himwich, H. E. (1947). Brain metabolism in man: unanesthetized and in pentothal narcosis. Amer. J. Psychiat., 103, 689-696.

Kety, S. S., and Schmidt, C. F. (1945). The determination of cerebral blood flow in man by the use of nitrous oxide in low concentrations. Amer. J. Physiol., 143, 53-66.

- - (1948). The nitrous oxide method for the quantitative determination of cerebral blood flow in man: Theory, procedure and normal values. J. clin. Invest., 27, 476-483.

Lassen, N. A., Munck, D., and Tottey, E. R. (1957). Mental function and cerebral oxygen consumption in organic dementia. Arch. Neurol. Psychiat. (Chic), 77, 126-133

Myerson, A., Halloran, R. D., and Hirsch, H. L (1927). Technic for obtaining blood from the internal jugular vein and internal carotid artery. Ibid., 17, 807-808.

Munck, O. and Lassen, N. A. (1957). Bilateral cerebral blood flow and oxygen consumption in man by use of Krypton ${ }^{85}$. Circulat. Res., 5, 163-168.

Peters, J. P., and Van Slyke, D. D. (1932). Quantitative Clinical Chemistry, Vol. II. Methods, pp. 229-352. Williams and Wilkins, Baltimore.

Reinmuth, O. M., Scheinberg, P., and Bourne, B. (1965). Total cerebral blood flow and metabolism Arch. Neurol. (Chic.), $12,49-66$.

Scheinberg, P. (1950a). Cerebral blood flow in vascular disease of the brain, with observations on the effects of stellate ganglion block. Amer. J. Med., 8, 139-147.

(1950b). Simultaneous bilateral determinations of cerebral blood flow and arterial-cerebral venous oxygen and glucose differences. Proc. Soc. exp. Biol. (N.Y.), 74, 575-578.

Shenkin, H. A., Harmel, M. H., and Kety, S. S. (1948). Dynamic anatomy of the cerebral circulation. Arch. Neurol. Psychiat. (Chic.), 60, 240-252.

Novak, P., Goluboff, B., Soffe, A. M., and Bortin, L. (1953). The effects of ageing, arteriosclerosis, and hypertension upon the cerebral circulation. J. clin. Invest., 32, 459-465. 